Rotas de Investigação sobre a formação do patrimônio cultural ...

\title{
Rotas de Investigação sobre a formação do patrimônio cultural da Bahia
}

\author{
Suely Moraes Ceravolo ${ }^{1}$
}

\section{Resumo:}

Apresenta-se o elenco de estudos sobre a constituição do patrimônio cultural da Bahia através de processos de musealização encadeados à Museologia, filiados ao GP Observatório da Muselogia na Bahia, linha História da Museologia na Bahia (Departamento de Museologia/PPG Museu/FFCH/UFBA - CNPq). Comenta-se o questionamento, o problema de pesquisa, o campo museal e o patrimônio cultural na Bahia. Parte-se da hipótese de que exposições, museus e coleções (públicas e privadas) consubstanciaram plataformas de sustentação para a construção desse patrimônio. O objetivo é identificar as variáveis, agentes e agências que intervieram nesse processo histórico. A metodologia baseada no levantamento, cruzamento e análise de fontes documentais revelam detalhamentos sobre instituições e personalidades baianas que responderam a demandas sociais e culturais locais. Conclui-se com um balanço dos trabalhos até o momento realizados aprofundando esse viés historiográfico.

Palavras-chave: museologia, exposição, museus, coleções, história da Museologia na Bahia.

\footnotetext{
${ }^{1}$ Professora Associada III, Departamento de Museologia, Faculdade de Filosofia e Ciências Humanas/Universidade Federal da Bahia, líder e pesquisadora do Grupo de Pesquisa Observatório da Museologia na Bahia, registrado no Conselho Nacional de Desenvolvimento Científico e Tecnológico (CNPq), docente do PPG Museu e PPG História da mesma Universidade. Endereço eletrônico: sumoce@ufba.br
} 


\section{Abstract:}

This paper analyses the studies that exist on the development of cultural heritage in Bahia via processes of musealization within the context of Museology, affiliated with the GP Bahia Museology Observatory, in the field of the History of Museology in Bahia (Department of Museology/PPG Museu/FFCH/UFBA - CNPq). Issues relating to research, the field of museology and cultural heritage in Bahia are evaluated based on the hypothesis that exhibits, museums and collections (both public and private) contributed to the development of support platforms for the construction of this heritage. The objective is to identify the variables, participants and entities that were involved in this historic process. The methodology based on the identification, cross-referencing and analysis of sources of information has brought to light details regarding Bahian institutions and personalities that are a response to local social and cultural demands. Finally, an overview is presented of the studies currently available to provide support to the paper's historiographic focus.

Keywords: museology, exhibits, museums, collections, history of Museology in Bahia.

\section{O questionamento}

A cidade do Salvador, capital do Estado da Bahia se destaca, no Brasil, por rico patrimônio arquitetônico, histórico, artístico e de diversas manifestações culturais, especialmente as de raiz afrobrasileira, chamando a atenção de turistas brasileiros e estrangeiros. Embora a concepção de patrimônio cultural tenha se ampliado no século $X X$, o tema precisa ser problematizado quando seus elementos se tornam naturalizados - úteis para preservar a hegemonia das classes dominantes (García Canclini, 1997). Justamente para ir de encontro a um panorama assimilado e divulgado, considera-se necessário investir no distanciamento crítico, na identificação de fontes documentais e análise, de modo a esclarecer, ao menos parte, os processos históricos que colaboraram ou não para selecionar o que chegou até nós. Coloca- 
Rotas de Investigação sobre a formação do patrimônio cultural ...

se, para tanto, algumas questões vinculadas à constituição do universo museal na Bahia: qual o papel e lugar desse universo para a sociedade baiana?; Quais as agências e agentes, estratégias e práticas que teceram, em condições determinadas, variáveis culturais, políticas, sociais e mesmo econômicas o ideário e respectiva materialização de certo patrimônio cultural para a Bahia?. Ou, em outras palavras, quais os regimes de historicidade, na expressão cunhada por François Hartog (2003), que intervieram no trabalho do presentismo sobre o passado, a cada momento esculpido e res-siginificado?

Com vistas a elucidar pontos dessa malha de interrogações constituiu-se a linha de pesquisa História da Museologia na Bahia, no escopo do GP Observatório da Museologia na Bahia, vinculado ao Departamento de Museologia da Faculdade de Filosofia e Ciências Humanas da Universidade Federal da Bahia (FFCH/UFBA) ${ }^{2}$ e, mais recentemente, ao Programa de Pós-Graduação em Museologia (PPG Museu) do mesmo departamento. Investe-se, nessa vertente, na busca de fontes documentais em arquivos e outras instituições soteropolitanas que dizem respeito a colecionadores e coleções, particulares ou públicas, exposições e museus de modo a aprofundar a abordagem historiográfica para consolidar esse viés de estudo.

$\mathrm{Na}$ perspectiva teórico-metodológica, compartilhamos a premissa que advoga a impossibilidade em compreender uma área do conhecimento (aqui, a Museologia) sem entender o processo histórico em que foi produzida. Ou seja, o "[...] a-historicismo é uma ilusão [...]"; perspectiva que desdobra a concepção de ciência como

2

GP em atuação desde 2004/ Conselho Nacional de Desenvolvimento Científico e Tecnológico (CNPq), conta também com a liderança do Dr. Marcelo Nascimento Cunha, outros pesquisadores e formação interdisciplinar (Museologia; História; Ciência da Informação; Artes Visuais). As linhas de pesquisa foram redefinidas recentemente: História da Museologia na Bahia; Abordagens Artísticas e Concepções estéticas nos museus; Museologia e Memória Afro-Brasileira < http://dgp.cnpq.br/dgp/faces/consulta/consulta parametrizada.jsf>. 
agente de deslocamento de limites em contínua ampliação (Kobashi, Smit, \& Tálamo, 2001). Em consonância com tal premissa, entende-se a importância da análise retrospectiva, pontuada em estudos de caso, para melhor compreender a construção do campo museal na Bahia, uma vez que se respondeu a similares contingencias que ocorreram no Brasil, correspondeu, por sua vez, a específicas demandas sociais e culturais. Acredita-se que, somente um conjunto de estudos pode alimentar análises mais abrangentes para, então, chegar às sínteses, e dessas à possível teorização. Como escreveu Tzvetan Todorov (1970) "[...] o melhor caminho para a teoria passa pelo conhecimento empírico preciso." ${ }^{3}$ (p. 81).

Para operacionalizar a proposta estabelecemos como eixo de observação os processos de musealização para averiguar a hipótese de que colecionadores, coleções, exposições e museus consubstanciaram plataformas de sustentação gerando concepções de patrimônio cultural na Bahia. Nessa angulação, convergem dois objetivos: a identificação dos aspectos particulares do que poderíamos chamar provisoriamente "museologia baiana", e a contribuição para a historiografia da Museologia no Brasil.

\section{O problema}

O patrimônio como tema se vê abordado por várias áreas do saber incluindo a Museologia em conexão com categorias de análise, a exemplo de cultura material e imaterial, preservação, políticas culturais, diversidade cultural, educação patrimonial dentre outras. Não cabe aqui voltar às raízes da noção de patrimônio (nacional) após a Revolução Francesa. Mas é interessante ressaltar a abordagem de Néstor Garcia Canclini para a América Latina demonstrando que o patrimônio cultural - "recurso menos suspeito" -, é o mais conveniente para garantir a cumplicidade social. Nessa obra o autor alerta para os perigos do 
Rotas de Investigação sobre a formação do patrimônio cultural ...

patrimônio como "dom" e das consequências do respectivo manejo e manipulação, contexto em que os museus se encaixam com perfeição como palcos da "teatralização do poder" (García Canclini, 1997 , p. 162). Afinal, com bastante facilidade, os museus, em razão dos objetos, transmutam ideias em exposições, materializando e dando a ver e admirar o imaginado, instituindo elementos para validar o compartilhamento (herança) e a transmissão de bens tidos como comuns (Poulot, 2009). O patrimônio sob a dinâmica das transformações, um dos substratos discursivos para justificar a formação pública ou privada de coleções, exposições e museus agregou e agrega novas interpretações, desejos e intenções.

Usa-se o termo, mais contemporaneamente, no plural trazendo à tona as expectativas de preservação cultural dos mais diversos grupos, atestando o alargamento das margens conceituais empurradas para mais além, mesmo que o direito à identidade e a diferença carreguem aspectos harmônicos e contradições expressas nas formas de sociabilidade. Escreveu José Reginaldo Gonçalves (2007) que patrimônio é uma das categorias do pensamento ocidental que oferece parâmetros para o "entendimento da vida social e cultural" (p. 108). Waldisa Rússio (1984) afirmou, décadas atrás, que preservar interliga a "idéia de patrimônio em si, e à idéia de cultura em si" (p. 63).

Há uma multiplicidade de abordagens para tratar do que vem - ou não - a ser a cultura (Coelho, 2008). Nesse verdadeiro leque de possibilidades encontra-se cultura no sentido de cultivo, e em concepções desenvolvidas por escolas (funcionalista, interacionista, outras) para explicar o social. O Coelho (1997), no Dicionário Crítico de Política Cultural aponta a visão antropológica de imaginário no sentido de formas invariantes (o efeito do mundo) e àquelas de contextos específicos, historicamente determináveis (efeito do discurso ou da representação), situando assim a noção de cultura:

... círculo metabólico, simultaneamente repetitivo e diferencial, que se estabelece entre o pólo das formas estruturantes, ou seja, 
das organizações e instituições (o instituído) - no qual manifestam-se códigos, formações discursivas e sistemas de ação -, e o pólo do plasma existencial, isto é, dos grupos sociais, das vivências, dos espaços, da afetividade e do afetual, enfim do instituinte. Esse circuito é ainda dito metaléptico - i.é, guiado pela intencionalidade do desejo nas trocas e substituições dos elementos, suas causas e conseqüências - e caracteriza-se por essa polarização e não por uma dicotomia, localizando-se a cultura nesse anel recursivo que estabelece e alimenta a circulação constante entre ambos os pólos (p. 105).

A noção de cultura como círculo metabólico e recursivo traz para a pauta das discussões, no âmbito do problema da investigação, a perspectiva relacional articulando dimensões - a das organizações, da ação, do discurso, do fazer e do sentir - presentes nas práticas e refletidas nos processos, caso da musealização.

Identificamos como elemento comum nessas proposições sobre cultura e patrimônio cultural a atuação dos agentes sociais, pois, nenhuma se concretiza sem essa presença e intervenção. Pode-se dizer que resultam da arte de construir ou edificar o social, o que Ihes dá realidade partilhada em interação (Berger \& Luckmann, 2010).

Nem só símbolos (linguagens), nem só matéria (objetos grosso modo), cultura e patrimônio decorrem da intencionalidade, ação e intervenção dando-lhes existência e substância para inventar tradições, para construir uma determinada visão de história, instituir a memória social, definir a identidade da nação ou regional arquitetando a face representativa para dizer de um "nós" antes frágil ou inexistente.

A orientação do projeto para observar a contiguidade da construção do campo museal e o do patrimônio na Bahia pode ser objetivada na investigação de processos de musealização, instalados como práticas culturais na sociedade baiana e, certamente, norteadas por diferentes concepções de patrimônio cultural revestindo "coisas" com atributos além da sua 
Rotas de Investigação sobre a formação do patrimônio cultural ...

materialidade. Aí, entende-se, o fulcro do problema da pesquisa nesse projeto a ser abordado na angulação da Museologia.

\section{O campo museal e patrimônio cultural na Bahia}

Na obra Conceitos-chave de museologia, campo museal se empregado como adjetivo refere-se a museu, e substantivo ao que Ihe é específico. O "conjunto de tentativas de teorização ou de reflexão crítica sobre o campo museal, ou ainda como a ética ou a filosofia do museal" corresponde à Museologia (Desvallèes \& Mairesse, 2013, p. 54). Importa comentar que o mapeamento de noções (conceitos) e as respectivas denominações (termos) condiz com o investimento no domínio Museologia para identificar a própria linguagem de especialidade e, consequentemente, o território conceitual, vocabular e semântico que tanto o situa como o delimita (Ceravolo, 2004a, 2004b). Exemplo disso se dá com musealização, correspondendo a um conjunto de ações sobre certos objetos que, ao serem deslocados para o abrangente campo museal, tornam-se evidência, conformando uma determinada "realidade cultural específica". ${ }^{4}$ O campo museal pode então ser compreendido como aquele que lida e dá ênfase a objetos selecionados, dotados de musealidade (Mensch, 1992) na condição de documentos (testemunhos), sujeitos a determinados procedimentos; segundo Waldisa Rússio, aplicáveis em "museu tradicional”, in-situ ou em "eco contexto" (Rússio apud Bruno, 2010, p. 125).

Os processos de musealização estão, portanto, anelados às atividades museais. Isso significa a mediação de procedimentos cujo fim volta-se para a salvaguarda de certo conjunto de bens considerado significativo para ser apreendido como herança social. Há, assim, uma ligação relacional entre musealizar e patrimonializar

\footnotetext{
${ }^{4}$ Musealização: "operação de extração, física e conceitual, de uma coisa de seu meio natural ou cultural de origem, conferindo a ela um estatuto museal, isto é, transformando-a em musealium ou musealia, em um 'objeto de museu' que se integre ao campo museal” (Desvallées \& Mairesse, 2013, p. 54).
} 
pelo desejo em resguardar determinados bens culturais, ou considerados como tal. Entretanto, para instituir um campo museal abrangendo o universo cultural pleno de objetos e significações atribuídas é preciso transformar a intenção em ação, daí decorrendo consequências modificadoras; entre um e outro se instala o discurso.

Consideramos que os colecionadores, coleções, exposições e museus correspondem à categoria lugar em relação à Museologia. A bem dizer são constructos concebidos e realizados por alguém ou por um grupo de enunciadores (produtores de discursos), os metamorfoseando em formas e conteúdos de acordo com determinada época ou período. Por isso, historicamente datados e encravados na malha social e dela continuamente dependente; sujeitos, portanto, a normas, sanções e modificações. Ótimos pontos de observação da produção de sentido que, longe de um equilíbrio simétrico, sofrem do embate de forças antinômicas (harmonia/conflitos, aceitação/rejeição) carreando efeitos do político (Verón, 1980).

Todavia, a dimensão dessas forças não se dá ao acaso e nem sem instrumentos de transmissão e reprodução de valores. Há protagonistas que ocupam certo locus social partilhando ou não o gosto, sensibilidades e saberes de acordo com padrões de época, encontrando na linguagem o recurso narrativo de modo singular, classificatório e distintivo se seguirmos o raciocínio bourdiano (Bourdieu, 1998). No Brasil, as camadas da elite intelectual foram responsáveis pela prática da "imaginação museal" não sendo essa, segundo Mario Chagas (2009), prerrogativa de profissionais museólogos. Na Bahia, não foi diferente considerando-se a estruturação social que dominou a dimensão cultural, como veremos mais adiante.

Delimitar o estudo de processos de musealização associados à constituição do patrimônio cultural na Bahia não foi, até o momento, abordagem privilegiada. No entanto, é preciso referenciar teses e dissertações produzidas em diferentes programas de pós-graduação da Bahia, ou em outras universidades 
Rotas de Investigação sobre a formação do patrimônio cultural ...

desse ou outros estados brasileiros. Sem qualquer intenção em desconsiderar os autores dessas investigações, centramo-nos aqui nos focos de pesquisa, em pontos localizados entre o século XVIII e $X X$ : estudos de cultura material e arte (balangandãs; objetos africanos e afro-brasileiros; vestuário, outros); exposição; coleções e colecionadores; criação de museus e ou instituições voltadas para a preservação do patrimônio segundo aproximações com a semiótica, antropologia e estudos multidisciplinares, história, ciência da informação e artes visuais. A lista se amplia mais recentemente com os trabalhos do PPG Museu/UFBA (além de outros programas, como dito).

Ressalta-se que, as questões colocadas pela angulação da Museologia, sem prescindir da bagagem teórica e metodológica de outras áreas do saber, assume as manifestações museais como legítimas, materializando ideias propositalmente postas em evidência ou deixadas ao largo, perdidas ou esquecidas em razão das escolhas realizadas pelos agentes atuantes no processo dessas construções culturais. Desse modo, os recortes e junções intelectuais operam como "vasos comunicantes", melhor observados em fendas sincrônicas, cuja expressão aflora nos interstícios do discurso, sustentando as aspirações dos sujeitos sociais e nas práticas que Ihes dá configuração exterior. Segue-se, assim, princípios específicos de concepção, funcionamento e organização.

Por um lado, o problema se coloca em razão da riqueza do tema a ser aprofundado e, por outro lado, é fundamental dar voz às instituições e personalidades baianas que atuaram de modo efetivo em redes locais e nacionais da cultura em diferentes períodos da história do Brasil. Logo, não estiveram ao largo do processo mas sim inseridos em movimentos formadores do ideário museológico brasileiro. Além disso, o Nordeste brasileiro, segundo o historiador Durval Muniz de Albuquerque (2001) foi inventado, estereotipado e marginalizado em várias de suas características. $\mathrm{O}$ autor sublinha as condições impostas pela redefinição de forças sociais no âmbito nacional desde a segunda metade do século XIX. A criação de 
museus - ao que poderíamos acrescentar as coleções e exposições - e de um patrimônio regional fez parte desse jogo de forças, pois, recursos significativos na formação da identidade nordestina (Viana, 2002).

\section{Balanço}

Se pesquisas alcançam resultados para as hipóteses que as motivaram acabam, por sua vez, descortinando outras questões. 0 caminho não é retilíneo. Faz curvas. Vai e volta e, ao cruzar o ponto anterior amplia-se na razão direta de novas pesquisas. Para uma rota que se iniciou com a investigação sobre o Museu do Estado da Bahia, criado em 1918, ${ }^{5}$ caminhamos nesse vai e vem para tempos pretéritos no século XIX e, no século posterior, até aproximadamente a década de 1970. (Ceravolo, 2011) O período de certa amplitude temporal encerra mudanças e permanências além de incorporar determinadas visões de história, passado, tradição, identidade e memória. Nesse transcurso, procura-se avançar em algumas variáveis: identificação das matrizes ideológicas inspiradoras da constituição do patrimônio cultural e campo museal na Bahia; os conflitos ou harmonização de interesses entre agentes e agências; os traços discursivos recorrentes e o repertório narrativo, enfim, os pontos de articulação responsáveis por concepções destinadas, por motivos diversos, a selecionar acervos anelando-os ao patrimônio cultural local (cidade do Salvador) e regional (Bahia).

A estratégia metodológica para o desenvolvimento das pesquisas dedica-se a localizar fontes documentais e bibliográficas para literalmente tecer - entrelaçar os fios - entre o viés museológico com o de outras áreas. Procuramos seguir nossa concepção de Museologia na condição de domínio do saber na enunciação sintetizada: se concretiza sobre indícios variados do patrimônio cultural e natural (o objeto), em qualquer lugar que eles 
Rotas de Investigação sobre a formação do patrimônio cultural ...

se apresentem (o lugar), através de procedimentos de preservação, conservação, documentação, exposição, educação, divulgação e disseminação de conhecimentos (os instrumentos) (Ceravolo, 2004a). Nessa perspectiva, os museus são um exercício possível da Museologia sem a eles se restringir; o que nos abre possibilidades no curso investigativo.

A linha cronológica, a bem da verdade, foi sendo construída em razão de pesquisas associadas: dissertações, monografias de final de curso (Museologia) e de cunho próprio com apoio de bolsas de iniciação científica (Programa Institucional de Bolsas de Iniciação Científica (PIBIC) /UFBA). ${ }^{6}$ Em relação ao PPG Museu, tem-se recentemente a discussão sobre museus-casa, (Britto, 2014) e em breve análises sobre colecionadores, coleção e museu, política pública para museus no Nordeste brasileiro, e a trajetória do próprio curso de Museologia na Bahia.

Comentamos a seguir, em linhas gerais e sequência cronológica (século XIX para o XX), os trabalhos que mais diretamente contribuem para questionar o objeto delimitado associado ao GP e linha de pesquisa. É o caso do estudo inédito sobre as exposições provinciais realizadas na Bahia no século XIX. A pesquisa demonstrou que o interesse da província em participar dos eventos nacionais, promovidos pelo Imperador Pedro II (18251891) para levar o Brasil a se apresentar nas Exposições Internacionais ou Universais - as vitrines do progresso -, teve motivos políticos de modo a posicionar o país no rumo da modernidade e não afastá-lo do circuito das nações, sem descuidar do mercado internacional. O Quadro 1, construído por Cinthia da Silva Cunha (2010, p. 58), situa, no tempo, os certames provinciais baianos:

Programa Institucional de Bolsas de Iniciação Cientifica - Universidade Federal da Bahia. 
Suely Moraes Ceravolo

\begin{tabular}{|l|c|c|c|}
\hline \multicolumn{1}{|c|}{$\begin{array}{c}\text { Exposições } \\
\text { Universais }\end{array}$} & Ano & $\begin{array}{c}\text { Exposições } \\
\text { Nacionais } \\
\text { Rio de Janeiro }\end{array}$ & $\begin{array}{c}\text { Exposições } \\
\text { Provinciais } \\
\text { Baianas }\end{array}$ \\
\hline Londres & 1851 & & \\
\hline Paris & 1855 & & $\mathbf{1 8 6 6}$ \\
\hline Londres & 1862 & 1861 & $\mathbf{1 8 7 2}$ \\
\hline Paris & $\mathbf{1 8 6 7}$ & $\mathbf{1 8 6 7}$ & $\mathbf{1 8 7 5}$ \\
\hline Viena & $\mathbf{1 8 7 3}$ & $\mathbf{1 8 7 3}$ & \\
\hline Filadélfia & $\mathbf{1 8 7 6}$ & $\mathbf{1 8 7 6}$ & \\
\hline Paris & 1878 & & $\mathbf{1 8 8 8}$ \\
\hline Buenos Aires & 1882 & & $\mathbf{1 8 8 9}$ \\
\hline São Petesburgo & 1884 & & \\
\hline Paris & $\mathbf{1 8 8 9}$ & & \\
\hline
\end{tabular}

Quadro 1 - Exposições Universais no século XIX, Nacionais e Baianas

O esforço em apresentar a melhor imagem do império brasileiro, ou seja, um país conectado ao ideário do desenvolvimento - civilizado, moderno, progressivo e culto escamoteou as contradições internas (caso da escravidão). Como expressa a autora, as exposições do XIX, iam além de feira de curiosidades. (Cunha, 2010) As fontes apuradas sobre os eventos na província da Bahia (catálogos, relatórios, folhetos informativos, guias e livros), indicam o grande empenho que despendeu para participar desses certames, interessada em formar um acervo para cuidar da reputação, lucros simbólicos e exportação. A Bahia enviou manufaturas e matéria prima, especialmente produtos, dentre eles, os agrícolas e minerais.

O estudo sobre o museu do Instituto Geográfico e Histórico da Bahia (IGHB; agremiação particular), inaugurado logo no início do período republicano (1894), nos levou à aspectos similares. A criação da agremiação, conjunção de letrados e elite política foi motivada para se tornar um centro dedicado à instrução, à ciência, à literatura e ao desenvolvimento da história justo no momento de transição política (entre o passado monárquico e o regime republicano); a ideia era alicerçar o futuro postulando um modelo 
Rotas de Investigação sobre a formação do patrimônio cultural ...

de educação. O passado devia servir de lição, razão para a construção da história pátria e a da Bahia. A proposta de modernização incluía de partida a criação do museu. Este deveria recolher: artefatos indígenas, objetos de homens notáveis do país, uma seção para a fauna natural da Bahia, e exposição dos objetos e produtos da natureza do solo baiano relativos a qualquer ramo da ciência a que estivessem filiados. A doação de sócios - e outros interessados - engrossou um conjunto museológico diversificado; eclético. Entretanto, o intento de cunho cultural (e civilizatório) não deixou de lado o interesse e importância em contar com um mostruário permanente de produtos para ser admirado por visitantes da Bahia. Entende-se o alinhamento com questões econômicas do momento para dar ênfase ao local e o regional, em relação a outros estados brasileiros. Não se pode descuidar de um fator significativo: a atenção ao mercado e, assim, aos negócios da Bahia. (Ceravolo, 2015) Ideia reforçada pela existência de um Museu Comercial no Rio de Janeiro (1905), com um serviço em Paris que daria suporte para a exposição de 1908 (Borges, 2001). 0 comércio de produtos baianos ocupava sim a pauta dos interesses da elite intelectual e, portanto, tema emparelhado ao discurso da cultura.

No que compete a preservação do patrimônio de forma mais direta tem-se a criação em 1927, da Inspetoria Estadual de Monumentos Nacionais uma década antes da criação do Serviço de Patrimônio Histórico e Artístico Nacional (SPHAN), em 1937, órgão que praticamente delimitou e federalizou a escolha de bens patrimoniais para o Brasil. A inspetoria baiana ficou como o arquivo, o museu e a Pinacoteca nas mãos do Estado formando o que chamamos células de preservação. Criada para tentar conter a evasão de bens materiais - escoamento que dilapidava o patrimônio da Bahia -, parece ter aberto a relação com o turismo. (Ceravolo, 2014) A vertente foi aprofundada no trabalho de Vanessa de Almeida Dócio (2014), demonstrando, dentre outros aspectos significativos nessa relação, a intenção do prefeito José Wanderley Pinho (1947-1951), na defesa do patrimônio edificado 
como elemento de geração de renda para o município e a intervenção na construção da memória estadual. Com maior evidência, em termos da linha mestra da pesquisa começam as questões relativas às políticas públicas em prol da preservação do patrimônio edificado.

No ano de 1959, esse mesmo patrimônio, reconhecido como documento histórico foi preocupação do intelectual baiano José Antonio do Prado Valladares, diretor do museu estadual e inspetor (1938 até 1959). ${ }^{7}$ Assíduo correspondente de Rodrigo Melo Franco de Andrade (1937 a 1969, diretor do SPHAN), colaborador do órgão federal, partícipe do círculo de estudiosos da arte no Brasil, publicou em jornais soteropolitanos um conjunto de notas sintomaticamente intituladas "Bahia ameaçada" (Dias \& Ceravolo, 2015) e "Conhece tua Cidade", ilustradas com fotografias. Ainda que o discurso estivesse alinhado às diretrizes do SPHAN, pautado no risco da perda (Gonçalves, 2002), José Valladares extrapola - a nosso ver, intencionalmente - o perímetro dos bens tombados pelo órgão federal mais circunscrito ao centro antigo. Ao ampliar o circuito desde a Cidade Baixa ao Rio Vermelho, deixa entrever praças e ladeiras, conjuntos edificados, solares e casinhas chamando o olhar do leitor para a "alma" da cidade. Critica enfaticamente o abandono. Sob seu escrutínio tratava-se da cidade do Salvador e não somente edificações representativas de certa arquitetura urbana; demolições e destruidores incêndios criminosos aconteciam simultaneamente à expansão de empreendimentos (e empresas) imobiliários. A cidade crescia prensada entre a modernização urbana (o novo) e a tradição (o antigo). Perdia, assim, o que lhe caracterizava. Não obstante fatos e eventos destrutivos, o turismo, mais uma vez, foi argumento de força para defender o patrimônio edificado. Turismo que trazia dividendos para os cofres da cidade alimentando, portanto, os negócios. (Ceravolo, 2016)

7 Sobre José Antonio do Prado Valladares ver Ceravolo e Santos (2007). 
Rotas de Investigação sobre a formação do patrimônio cultural ...

Os efeitos do colecionismo foram ampliados com a análise das exposições temporárias promovidas pelo Instituto Feminino da Bahia (IFB), escola particular para mulheres na cidade do Salvador. Criado por Henriqueta Martins Catharino (1886-1969), personalidade da sociedade baiana, fez constar do projeto pedagógico três segmentos museológicos: o Museu de Arte Antiga, o de Arte Popular, e o Geológico Econômico (Museu de Ciências Naturais ou Museu de História Natural) para apoiar aulas práticas. Em sede construída especialmente para instalar a escola e cursos, pensão e restaurante abrigou objetos de arte decorativa, indumentária e arte popular. Foi possível abordar as exposições temporárias (1920-1968) com base na proposição de Pierre Bourdieu (2003), certificando a escola como reprodutora de modelos de percepção e mantenedora da estrutura das relações de classe, a partir de noticias publicadas em jornais cuidadosamente arquivadas em um álbum (institucionalmente denominado "Recordando...") e opúsculos compondo a base documental. As exposições foram abordadas na perspectiva de transmissoras de mensagens que evidenciam relações através de objetos, manipulam linguagens e são recursos de poder (Britto, 2014; Cury, 2005; Davallon, 2003) e, a nosso ver, articulam a grafia (composição dos objetos entre si ou com outros itens) e construção semântica de compreensão latente no discurso ou narrativa expositiva, determinando os limites polarizados do espaço social. Da sistematização cronológica das exposições, observamos dois momentos distintos: 1920 a 1941, as mostras davam visibilidade à produção das obras assistenciais com fins de benemerência (trabalhos manuais, prendas domésticas; trabalho feminino), e de 1941 a 1968, um progressivo deslocamento para a arte. Concluímos que essa escola sancionou determinadas categorias de percepção, e as coisas serviam de lição para as senhoras ou senhoritas que precisavam aprender, ou rememorar, o convívio com um fausto passado. As exposições carregadas de propósitos classificatórios nutridos no poder performativo, autorizado pelo grupo, ajudaram a cultivar o status quo e as qualidades e habilidades esperadas da 
mulher baiana: perfeição, beleza, delicadeza, gosto, arte e perícia. (Ceravolo, 2016) Apercebemo-nos das questões de gênero influenciando a formação do acervo de forma distinta, caso da direção dada ao acervo do IGHB e o do Museu do Estado, conjuntos formados mais por homens. Não obstante essa distinção, a agenda geral para a formação de conjuntos museológicos era materializar e rememorar um passado desse modo tornado tradição. No IFB as mostras temporárias primaram pelo discurso para as mulheres; as de elite.

Há outros pontos nessa malha para os quais se recolhe fontes documentais de modo a detalhar o trajeto investigativo em curso. O que pudemos averiguar até o momento reforça a ênfase em ditar e manipular a escolha de bens móveis e imóveis pelas mãos e voz da parte do social letrada, política e economicamente bem situada. A preservação se dá em 'defesa' de seus próprios valores e escolhas. O negro não aparece. Ou melhor, aparece nos artefatos recolhidos aos terreiros de candomblés no Museu do Estado e no Museu do Instituto Geográfico e Histórico da Bahia. No Instituto Feminino da Bahia nas roupas das crioulas (parte do acervo) ou então, ao vivo, para servir iguarias em eventos ali realizados. ${ }^{8} \mathrm{O}$ mesmo vale para os indígenas; deles só artefatos. Exclusão já conhecida; as fontes só a reforça em nuances.

Constata-se a mobilização na e para a Bahia da imaginação museal a que se refere Mario Chagas, anteriormente citado. A maneira como foi se instituindo o patrimônio cultural esteve profundamente ligada à classe dominante que, por sua vez, via-se próxima e articulada ao que ocorria no país e no mundo ocidental em movimento inerente e conectado da dinâmica cultural. Se tal dinâmica, efeitos e impactos não são propriamente inéditos, à luz da identificação sistemática, proporcionada pelo levantamento e cruzamento de fontes documentais e a produção discursiva revelam, passo a passo, os agentes e ações de modo mais esquadrinhado. Há que se contar com antecedentes e inspirações.

8 Ver Silva (2015). Sobre a coleção do IFB, ver Queiroz (2014). 
Rotas de Investigação sobre a formação do patrimônio cultural ...

Citamos a proposta de Wanderley Pinho para constituir, dentro do IGHB, uma Comissão dos Monumentos e das Artes, em 1917, inspirado no escritor José Duarte Ramalho Ortigão (ou Ramalho Ortigão) e sua obra $O$ culto da arte em Portugal (1896). ${ }^{9}$ Posteriormente, em 1930, W. Pinho elaborou projeto de lei para proteger os bens nacionais cuja ação seria levada a cabo por uma Inspetoria de Defesa do Patrimônio Histórico-Artístico Nacional, apoiada por congêneres estaduais. No cargo de prefeito se empenhou muitíssimo na encenação cívica e pública, teatralização da história a céu aberto segundo Alan Santos Passos (2016), quando da comemoração dos 400 anos da cidade do Salvador. (Passos, 2016)

Tem-se, em linhas gerais, na relação musealizaçãopatrimonialização (e vice-versa): o uso do passado no rastro sintoma de presença e ausência ${ }^{10}$-, de certa aura da Bahia. Do território, os produtos e ou amostras para apresentar a riqueza do solo baiano, compondo acervos em exposições e museus incentivando o olhar do visitante. Certo plano da cartografia social (agentes e agências), mapeado na formação de coleções (bens móveis), escolhidas e acolhidas em museus, expostas em vitrines, posicionando os discursos descritivos e performativos nos domínios da elite, cheios de intenções distintivas, portanto, excludentes e mantenedores do status quo. A presentificação do passado através igualmente de exemplares da arquitetura pretérita (bens imóveis) na cidade do Salvador, na condição de documentos da história quando o antigo, valorizado pelo afluxo crescente do turismo, perde-se frente à inexorável expansão imobiliária ao tempo em que a pretendida feição moderna se instalava dando lugar ao rasgo

9 Conforme documentado no Anexo IV em Proteção e Revitalização do Patrimônio Cultural no Brasil: uma trajetória. (IPHAN, 1980, p. 46-53) <

10 Jeanne Marie Gagnebin comenta a complexidade paradoxal do conceito de "rastro" para discuti-lo na perspectiva de Walter Benjamin (grifo da autora) no texto "Apagar os rastros, recolher os restos" . In S. Sedlmayer \& J. Ginzburg (Org.). Walter Benjamin: restro, aura e história. (pp. 27-38). . Belo Horizonte: Ed. UFMG, 2012. 
periférico crescente ${ }^{11}$. Se há algo nessa conjunção que confirma o magnetismo do simbólico em nome da memória, identidade e tradição há, igualmente, questões outras a exemplo de uma variável que, em nossa perspectiva, salienta a probabilidade detectada: as tramas, ainda opacas, dos negócios e turismo em conjuntura sutil na salvaguarda do patrimônio cultural. Em camada mais profunda e não necessariamente oposta - ajustadas propõe Simonie Scifoni (2015) -, essa perspectiva merece investigação, pois, mais um fator que desnaturaliza as intenções, por vezes puristas, em se tratando da constituição de um patrimônio cultural. No entanto, implicou e implica na sua escolha e formação. Rota que instiga; o imaginado tem seu preço.

\section{Referências}

Albuquerque Junior, D. M. de. (2001). A Invenção do Nordeste e outras artes. Recife: FJN. Ed. Massangana; São Paulo: Cortez.

Berger, P. \& Luckmann, T. (2010). A construção social da realidade. Petrópolis: Vozes.

Borges, M. E. L. (2001). Exposições universais e museus comerciais: entre o efêmero e o permanente. In M. E. L. Borges (Org.), Inovações, coleções, museus (145-166). Belo Horizonte: Autêntica Ed..

Bourdieu, P. (2003). Gostos de classe e estilo de vida. In R. Ortiz (Org.), A sociologia de Pierre Bourdieu (pp. 145-166). São Paulo: Olho d'água.

Bourdieu, P. (1998). Descrever e prescrever: as condições e os limites da eficácia política. In P. Bourdieu. A economia das trocas lingüísticas. (pp. 117-128). São Paulo: EdUSP.

11 Sobre o tema ver Sampaio (2005). 
Rotas de Investigação sobre a formação do patrimônio cultural ...

Britto, C. C. (2016). Gramática expositiva das coisas: a poética alquímica dos museus-casas de Cora Coralina e Maria Bonita. (Dissertação). Universidade Federal da Bahia, Salvador.

Britto, C. C. (2014). A terceira margem do patrimônio: o Rio Vermelho e a configuração do habitus vilaboense. Diálogos, 18(3), 975-1004. Disponível em: http://www.uem.br/dialogos/index.php?journal=ojs\&page=arti cle\&op=view\&path[]=992\&path[]=pdf_671

Bruno, M. C. O. (Org.), (2010). Waldisa Rússio Camargo Guarnieri. Textos e contextos de uma trajetória profissional. São Paulo: Pinacoteca do Estado : Secretaria do Estado da Cultura : Comitê Brasileiro do ICOM.

Chagas, Mario de Souza. (2009). Imaginação Museal - Museu, Memória e Poder em Gustavo Barroso, Gilberto Freyre e Darcy Ribeiro._Rio de Janeiro : MinC/IBRAM.

Ceravolo, S. M. (2004a). Da Palavra ao termo. Um caminho para compreender Museologia. (Tese). Universidade de São Paulo, São Paulo.

Ceravolo, S. M. (2004b). Em nome do céu, o que é museologia?” Perspectivas de Museologia através de publicações. Revista do Museu de Arqueologia e Etnologia, 14, 311-34. Disponível em: http://www.revistas.usp.br/revmae/article/view/89693/92515

Ceravolo, S. M. (2011). O Museu do Estado da Bahia: entre ideais e realidades (1918 a 1959). Anais do Museu Paulista, 19(1). Disponível em: http://www.scielo.br/scielo.php?script=sci_arttext\&pid=S010147142011000100007

Ceravolo, S. M. (2015). Brazilian Ark: The Museum of the Instituto Geográfico e Histórico da

Bahia (1894-1927). Museum History Journal, 9(1), 1-15.

Ceravolo, S. M. (2014). A Inspetoria Estadual de Monumentos Nacionais do estado da Bahia: do discurso à ação (1927-1938). In A. M. Magalhães \& R. Z. Bezerra (Org.). 90 anos do Museu Histórico Nacional em debate. (pp. 122-142). Rio de Janeiro: Museu Histórico Nacional. 
Ceravolo, S. M. \& Santos, D. C. dos. (2007). Apontamentos sobre José Antonio do Prado Valladares - "um homem de museu". Cadernos do CEOM, 20(6), 195-222. Disponível em: http://bell.unochapeco.edu.br/revistas/index.php/rcc/article/vi ew/2025/1106

Ceravolo, S. M. (2016). A cidade do Salvador: "memória a céu aberto" e a disputa de sentidos na preservação do patrimônio arquitetônico civil (1959). In Anais do II Seminário Internacional em Memória Social. Rio de Janeiro: PPGMS/Unirio. Disponível em:

http://seminariosmemoriasocial.pro.br/wpcontent/uploads/2016/03/A028-SUELY-MORAES-CERAVOLOnormalizado.pdf

Ceravolo, S. M. (2016). Exposições temporárias para as "senhoras e senhoritas" da sociedade baiana: o discurso performativo do Instituto Feminino da Bahia (1920 a 1968). In V Congresso Sergipano de História e $V$ Encontro Estadual de História da ANPUH. Aracaju: ANPUH.

Coelho, T. (2008). A cultura e seu contrário. Cultura, arte e política pós 2001. São Paulo: Iluminuras: Itaú Cultural.

Coelho, T. (1997). Cultura. In Coelho, T. Dicionário crítico de política cultural. São Paulo: Iluminuras.

Cunha, C. da S. (2010). As Exposições Provinciais do Império: a Bahia e as exposições universais. (Dissertação). Universidade Federal da Bahia, Salvador. Disponível em:

http://www.ppgh.ufba.br/wp-content/uploads/2013/09/As-

Exposi\%C3\%A7\%C3\%B5es-Provinciais-do-Imp\%C3\%A9rio.pdf

Cury, M. X. (2005). Comunicação museológica: uma perspectiva teórica e metodológica de recepção. (Tese). Universidade de São Paulo, São Paulo.

Davallon, J. (2003). Pourquoi considérer l'exposition comme un média ? MédiaMorphoses, 9, 27-30. Disponível em: http://documents.irevues.inist.fr/bitstream/handle/2042/2327 5/2003_09_27.pdf?sequence=1\&isAllowed=y 
Rotas de Investigação sobre a formação do patrimônio cultural ...

Desvallèes, A. \& Mairesse, F. (Ed.), Conceitos-chave de Museologia (B. B. Soares \& M. X. Cury, tradução e comentários). São Paulo: Comitê Brasileiro do Conselho Internacional de Museus: Pinacoteca do Estado de São Paulo: Secretaria de Estado da Cultura. Disponível em:

http://icom-portugal.org/multimedia/conceitos-chave\%20de $\% 20$ museologia.pdf

Dias, C. M. de; Cerávolo, S. M. (2015). "Bahia Ameaçada": a visão de patrimônio cultural arquitetônico de José Valladares (19581959). Revista Eletrônica do Programa de Pós-Graduação em Museologia e Patrimônio, 8(1), 119-137. Disponível em: http://revistamuseologiaepatrimonio.mast.br/index.php/ppgp mus/article/viewFile/389/372

Dócio, V. de A. (2014). Sob o signo da pedra e cal: trajetória da política de preservação do patrimônio histórico e arquitetônico no Estado da Bahia (1927-1967). (Dissertação). Universidade Federal da Bahia, Salvador. Disponível em: http://www.ppgh.ufba.br/wp-content/uploads/2015/11/Sob-oSigno-da-Pedra-e-Cal.pdf

García Canclini, N. (1997). O porvir do passado. In N. García Canclini. Culturas híbridas: estratégias para entrar e sair da modernidade. (pp. 159-204). São Paulo: EdUSP.

Gonçalves, J. R. S. (2007). O espírito e a matéria: o patrimônio enquanto categoria de pensamento. In Antropologia dos objetos: coleções, museus e patrimônios (pp. 108-116). Rio de Janeiro: IPHAN/DEMU.

Gonçalves, J. R. S. (2002). A retórica da perda: os discursos do patrimônio cultural no Brasil. Rio de Janeiro: Ed. UFRJ/IPHAN.

Hartog, F. (2003). Tempo, história e a escrita da história: a ordem do tempo. Revista de História, 148(1), pp. 9-34. Disponível em: www.revistas.usp.br/revhistoria/article/view/18952

Instituto do Patrimônio Histórico e Artístico Nacional. (1980). Proteção e revitalização do patrimônio cultural no Brasil: uma trajetória. Brasília: Secretaria do Patrimônio Histórico e Artístico Nacional. Disponível em: 
http://portal.iphan.gov.br/uploads/ckfinder/arquivos/Protecao _revitalizacao_patrimonio_cultural(1).pdf

Kobashi, N., Smit, J. W., \& Tálamo, M. de F. G. M. (2001). A função da terminologia na construção do objeto da Ciência da Informação. Datagramazero. Revista de Ciência da Informação. 2(2). Disponível em: http://www.dgz.org.br/abr01/Art_03.htm

Mensch, P. van. (1992). Towards a met/hdology of museology. (PhD thesis). Unversity of Zagreb, Zagreb.

Passos, A. S. (2016). A Cidade de Salvador e os seus 400 anos: política, história e usos do passado (Bahia, 1949). (Dissertação). Universidade Federal da Bahia, Salvador.

Poulot, D. (2009). Uma história do patrimônio no Ocidente, séculos XVII-XXI. Do monumento aos valores. São Paulo: Estação Liberdade.

Queiroz, M. S. (2014). Museu, memória e a morte: um estudo a partir da coleção de quadros de cabelos da Fundação Instituto Feminino da Bahia. (Dissertação). Universidade Federal da Bahia, Salvador. Disponível em:

http://www.ppgav.eba.ufba.br/sites/ppgav.eba.ufba.br/files /producaocientifica/2014_-_marijara_souza_queiroz.pdf

Rússio, W. (1984). Texto III. In A. A. Arantes (Org.), Produzindo o passado. Estratégias de construção do patrimônio cultural. (5978). São Paulo: Brasiliense.

Sampaio, A. H. L. (2005). Formas urbanas: cidade real \& cidade ideal. Contribuição ao estudo urbanístico de Salvador. Salvador: Quarteto: PPGAU-FAUBA.

Scifoni, S. (2015). Patrimônio como negócio. In A. F. A. Carlos, D Volochko \& I. P. Alvares (Orgs.), A cidade como negócio. (209226). São Paulo: Contexto.

Silva, J. A. F. (2015). A representação das mulheres negras nos museus de Salvador: uma análise em branco e preto. (Dissertação). Universidade Federal da Bahia, Salvador. Disponível em:

https://repositorio.ufba.br/ri/bitstream/ri/18548/1/JOANA\%20 SILVA.pdf 
Rotas de Investigação sobre a formação do patrimônio cultural ...

Todorov, T. (1970). As estruturas narrativas. São Paulo: Ed. Perspectiva.

Verón, E. (1980). A produção de sentido. São Paulo: Ed. Cultriz: EdUSP.

Viana, H. do N. (2002). Os usos do popular: coleções, museus e identidades, na Bahia e em Pernambuco, do início do século à década de 1950. (Tese). Universidade de São Paulo, São Paulo. 
Suely Moraes Ceravolo 